\title{
Exploring the learning experiences of older mature undergraduate students
}

Nick Pearce, University of West London

\section{Email: nick.pearce@uwl.ac.uk \\ DOI: https://doi.org/10.5456/WPLL.19.1.1x}

\begin{abstract}
Mature students have been a significant feature of UK higher education for at least 40 years. Categorising all undergraduates who started their degrees over the age of 2, as mature masks significant diversity. Older mature students have been shown to get better degree outcomes than younger mature students and young students. This study explores the learning experience of six older mature students, who started their studies over the age of 40, in order to better understand this understudied group. The findings suggest that confidence is of critical importance in underpinning the experience of this group, and that increased confidence leads to better time management and more integration into the wider student body. This has implications for lifelong learning, where developing strategies to improve the confidence of these learners can help accelerate their integration into the student body, and may have a positive impact on their retention.
\end{abstract}

Key words Mature student, older mature student, lifelong learning

\section{Introduction}

For many young adults, going to university is a transformational rite of passage marking the transition from being a dependent living at home to becoming an independent graduate, although recent trends have diminished this transformation (Lewis et al., 2016). For older learners, going to university clearly holds different meanings, although it can still be regarded as a transformational experience. Indeed, because the identities and perspectives being transformed are more entrenched, the effect can be greater with age (Mezirow, 1978). Alongside the personal transformation, is the experience 
of being a mature student in an environment designed around the young learner.

The Higher Education Statistics Authority (HESA) Higher Education Statistics Agency definition of "mature students", which is widely used in the UK is "those who are aged 21 or over, at 30 September of the academic year in which they are recorded as entering the institution" (HESA, 2016). In 2014/15 the percentage of UK-domiciled, full time, first year mature students was 27.6 per cent, which includes 10.7 per cent who were over 30 years old (HESA, 2016). These figures mask considerable variation across part time degrees (90.5 per cent or whom are mature) and across the type of institution, with mature students most likely to go to post-1992 institutions (Johnes, 2014).

Commenting on a 6 per cent rise in mature students being accepted on to courses in 2014, Les Ebdon, the Director of Fair Access to Higher Education said:

"Mature students are more likely to be from disadvantaged backgrounds so this increase is good news for social mobility, and ultimately for the economy and society as a whole. For many people who did not go to university straight from sixth-form or college, mature study offers a valuable second chance to gain the qualifications they need to succeed in the workplace" (OFFA, 2014)

I would add to this that, in the context of rising tuition fees, the idea of attending university straight after school seems less appropriate, as many people may take longer to decide which course to study, or whether to study at university at all. Mature learners are clearly an important aspect of lifelong learning.

However, using the HESA definition for a mature student masks a great deal of variation. In my teaching experience, I have taught undergraduates who are over 60 years old, and a number in their 30s, 40s and 50s. The background experiences, support and expectations of these students will vary 
greatly, and will differ from mature students in their 20s. This article will attempt to describe the experiences of 'older' mature learners, those who started their undergraduate degree while aged over 40 years old. This study emerged from the author's experience teaching on a foundation programme, which included a number of older mature students. Of particular interest were the factors outside the classroom that may have shaped the student experiences within it, their physical learning environment, their use of online resources and how they experienced the classroom.

This data cannot be used to compare their experiences with other mature young students, but will hopefully contribute to the debate about mature students, and help inform future discussions of mature learners in general, and of older mature students in particular.

The next section will review the literature on mature students, focussing on their learning experiences, and any work that explores the diversity within the cohort of mature learners. The following section will outline the methodology I used to explore the experiences of a group of older students. The experience of these students will then be discussed, which will then inform the final section which will discuss the implications for this on teaching and teachers in Higher Education.

\section{Recognising the mature student}

Mature students were a feature of early higher education provision, at least since the time of the University of London's external degrees and the provincial colleges (Brady and Brady, 1998). A number of developments led to increasing numbers of mature students in the later part of the 20th century. The rapid expansion of the higher education sector in the 1960s and then the 1980s led to calls for a more diverse student body (Scott, 1998, Smith, 2008). In the 1980s, demographic changes meant an expected decline in 18 year old entrants, which exacerbated this recruitment pressure. This was explicitly 
linked to mature students by the-then education secretary, Kenneth Baker, in 1989, when he said universities "will have to re-orient themselves in new ways to recruit students not drawn from the traditional 18 year old class" (cited in Wakeford, 2006). Linked to this, the establishment of the Open University in 1969 created the opportunity to reach large numbers of mature learners via distance learning (Tunstall, 1974).

The development and rapid expansion of access courses in the 1980s provided a 'third route' (after ' $A$ ' levels and NVQs), targeted at mature learners who wished to enter university (Parry and Wake, 1990, Reay et al., 2002, Wakeford, 2006). These access courses were provided by Further Education colleges, and a later development saw the emergence of integrated foundation years provided by Higher Education providers, targeting a variety of non-traditional groups including mature learners (Davies and Parry, 1993, Marshall, 2013).

This rise in the prominence and importance of mature learners led to increased attention from educational researchers, who were interested in the experiences and performance of this group compared to young students.

In an early piece of research, Nisbet and Welsh conducted a study of 177 mature students who entered their university over a three-year period (196567). This was a 70 per cent response rate of the 257 mature students identified, which already suggests a significant body of mature students at Aberdeen University at this time (Nisbet and Welsh, 1972). The median age of these students was 30, but there was a wide spread, with 11 per cent of their respondents over the age of 40 (Nisbet and Welsh, 1972). Their study focussed on a range of factors, noting that:

"The mature students in this survey tend to come from the same section of the population and the same schools as the young direct entrants. In performance, they differ little from the younger students" (Nisbet and Welsh, 1972: 207) 
There was little difference noted in degree performance across the age ranges, although the authors only compared the performance of under and over-30s.

Their findings, that the diversity within the mature students' backgrounds was similar to that of the younger students, is noteworthy in relation to the quote from Kenneth Baker, although the authors acknowledge that "the category of 'mature student' is clearly too heterogeneous to draw firm conclusions which apply to all” (Nisbet and Welsh, 1972, p. 207).

Other research focussed on the performance of mature students in their university studies. An early study found that degree performance improved with age, up to the age of 40 , before declining back to the levels of the general undergraduate population (Bourner and Hamed, 1987). This is consistent with other quantitative studies which have found higher levels of achievement for mature students who have completed their undergraduate studies (Hoskins et al., 1997, Richardson, 1994). The Hoskins study found that students over the age of 25 out-performed students aged 21-25, who themselves fared better than non-mature students (Hoskins et al., 1997). The authors suggest the improved performance of older students may reflect the fact they are more often studying in order to develop themselves personally rather than as a means to an end (Hoskins et al., 1997, p. 325).

Focussing on the performance of mature students on graduation can mask the differential completion rates for this group (Hatt et al., 2002). This can be due to range of internal and external factors, but may also be a product of a higher education system which is still, in many cases, designed around the residential, full time, young student (Christie et al., 2005, Tuckett, 1990).

Whilst in purely academic terms the mature students who complete their studies have been shown to perform well, their experience of higher education can still be a limited one (Christie et al., 2005). These students described themselves as 'day students' who were combined their studies with living at 
home and pre-existing parental or employment responsibilities. They missed out on the social aspects of university life highlighted by the younger students, and also felt excluded from networks where important informal information was shared (Christie et al., 2005).

A more recent study explored this issue further, describing how mature students negotiate a culture of higher education dominated by younger students (Mallman and Lee, 2014). This study is interesting for exploring both the experiences of mature students in a particular first year course with a large mature intake, and the experiences of the younger students, who expressed negative emotions at the mature students for some of their behaviours (such as a willingness to ask questions in class (Mallman and Lee, 2014). Nonetheless, it is clear that the mature students felt stigmatised and excluded from the dominant student culture.

Another factor affecting completion of mature students will be the increased incidence of parenthood and other caring responsibilities, although these responsibilities are strongly gendered (Brooks, 2011, Scott et al., 1996). A narrative approach looking at the experiences of 21 mature students further complicated the gendered nature of studying at university (Britton and Baxter, 1999). This study identifies four narratives amongst mature learners: struggling against the odds; unfulfilled potential; credentialism; and selftransformation. These narratives are gendered and not equally available to men and women in order make sense of their experiences (Britton and Baxter, 1999).

So far then there has been some attention in the literature to differences within the mature student group, particularly around gender and some age categories. Whilst a lot of the literature make a distinction between older and younger mature learners at 25 , there is no reason to suppose this division is especially meaningful. This study explores the experiences of a number of older mature students, who had started their studies over the age of 40 . The 
aims were to discover to what extent their experiences reflect the wider literature on mature learners, and to inform future policy and practice to encourage further lifelong learning amongst this group.

\section{Methodology}

This study was based at a medium-sized, old (pre-1992) Russell Group university in England. Universities of this type tend to have a low number of mature students than post-1992 ones (Johnes, 2014). As the study was focussed on a particular subset of these students, the population of older mature students from which to draw a sample was always going to be very small. The sample for this study were recruited through the foundation centre of this university, which targeted mature learners (amongst other groups) and for whom the author worked. As previously mentioned, the foundation year is a method of enabling access to Higher Education, but recruiting respondents in this way would ignore older mature students with recent level 3 qualifications enabling direct entry. As the mature students recruited would be entering without recent educational experiences, they are 'returners' rather than 'interrupters' and are therefore more likely to succeed (Baxter and Hatt, 1999).

The researcher was interviewing former students, and this raises its own methodological challenges. Clearly carrying out research in this way was convenient with access and rapport easy to establish, but it needs to be acknowledged that this kind of insider research brings with it specific challenges. More specifically, three issues have been identified: informant bias, interview reciprocity and research ethics (Mercer, 2007).

In this instance, informant bias was a potential issue as the students may have wanted to present a more diligent image of their studies than was in fact the case. In fact the interview responses represented a candid view of the 
struggles and challenges faced by this group. This level of candour may have been helped by the rapport and relationship formed over the course of the foundation year, and further helped by the fact that the students had completed the year, and so were no longer in a pedagogic relationship with the interviewer.

A further complication is that a number of the interviewees knew one another and discussed the interviews with each other prior to meeting the researcher. In this sense these conversations would be likely to influence the data collected, especially if based on misunderstandings about the nature of the research being carried out.

Interview reciprocity refers to the degree to which both the interviewer and interviewee contribute to the data collected. This can be effected by the structured nature of the interview schedule, and for these exploratory interviews a semi-structured interview was chosen, which may have increased the possibility of the interviewer influencing the data and decreased its comparability and generalisability.

Research ethics was an important concern for this study. Informed consent was obtained, and the objectives of the research were clearly explained. Anonymity was another important concern, especially when dealing with such a small sample from a small population of interest. In order to best preserve the anonymity of my respondents, I will only be giving limited demographic information about them. The names of the interviewees are pseudonyms.

Table 1 Basic demographic information about respondents

\begin{tabular}{|l|l|l|}
\hline Anonymised name & Sex & AGE \\
\hline Annabel & F & Mid-40s \\
\hline Brenda & F & $50 \mathrm{~s}$ \\
\hline Catherine & F & $50 \mathrm{~s}$ \\
\hline
\end{tabular}




\begin{tabular}{|l|l|l|}
\hline David & M & Early 40s \\
\hline Eric & M & Early 40s \\
\hline Frank & M & Early 60s \\
\hline
\end{tabular}

All the students progressed to departments in the faculty of social sciences between 2013 and 2015. There was not an opportunity to interview students from other faculties, so disciplinary differences cannot be explored in this study.

\section{Results}

The interviews were recorded and transcribed and thematically coded to look for common themes. Four themes emerged: confidence, pressures of time management, difficulties in studying socially and use of technology.

\section{Confidence}

The issue of confidence arose in all of the interviews, but manifested in different ways, and at different points in the students' learning journeys. For some of the respondents the confidence issues arose prior to starting their studies: "I was worried that I wouldn't be able to do it" (Annabel). Despite the lack of confidence prior to applying, all of my respondents had made the decision to apply: "I didn't have any confidence to apply for anything. I knew what I didn't want in my new life, and what I didn't want was to be stuck in that same place, working in a crappy job just to keep four walls around me" (Brenda).

The motivations for studying later in life varied, but often related to addressing the issue of confidence, where becoming a mature student was part of a deliberate strategy for building up confidence. "I decided that I needed to get some confidence and prove that I wasn't a total idiot" (Eric), "I just thought that at my age I was on the scrap heap. I honestly did and I thought, 
right I'm going to do something to prove that I can do something and that I'm not a waste of time and space" (Catherine).

These issues were not resolved at the start of the course, but cropped up at various points, such as submission of assignments: "the hardest thing for me was handing in an essay, for somebody to criticise the level of ability that I have, which was a gnat's ability" (Frank). Later in the same interview, a similar issue arose about seeking help from the department he had joined (after completing the foundation year): "I didn't dare go to the [department], it took me 2 months to go there" (Frank).

\section{Pressures of time management}

A further issue to emerge in the interviews was time management, in particular managing student and non-student life. None of the respondents lived in university accommodation and all commuted varying distances for classes, in sharp contrast with the general undergraduate population, for whom the vast majority lived in halls. This clearly impacted on their overall student experience: "I find that a lot of my enjoyment of university life is taken away because of time pressures. I always feel pressured" (Annabel).

Related to the earlier issues of confidence, many of the older mature students had unrealistic expectations on how many hours they should spend studying: "Some people can write an essay in two days, for me it was two weeks." (Catherine).

External factors, such as family and work pressures, weighed heavily on a number of the students: "being mature those external factors, like family, weigh heavily" (David).

Overall, the students painted a pretty harried picture of their studies, although this could have been influenced by the fact they were being interviewed in the early stages of their studies. A number acknowledged that they had 'calmed down' since the start, realising that they could achieve good marks with less effort as their confidence increased. 


\section{Difficulties in studying socially}

All the respondents described some level of difficulty in socialising with other students, although this was not limited to interactions between mature and young students: "as a mature student most of the other people on the course were either a heck of a lot younger than me or they were more my age but had their own families in the local area so they already had their lives there" (Brenda).

Some respondents acknowledged that the isolation was, at least in part, self-imposed: "well the anxiety from my point of view was feeling a bit alienated because of my age, and it's true. That's what it is. In lectures sometimes you get speaking to people before the lecture, or seminar, sometimes you need to work in groups or with partners but in between lectures there's nothing. I go off and do my thing, everybody goes back to their halls or whatever" (Annabel).

Nevertheless, there was evidence that mature students socialised together, especially after they had moved into their departments: "a lot of the [department] students are really young, living in college, partying things like that so the foundation group always sticks together" (David). The mature students did not necessarily study together, but there was an important element of social support: "we would gather together to have a coffee afterwards and we'd maybe have a little discussion, but we wouldn't do this group thing where we'd get our books out and our writing pads and put something together, which I think is something I think the young folk seem to do quite a lot" (Catherine). This may be related to the lack of confidence expressed earlier, as Catherine later acknowledges the value of study groups: "maybe it would have been useful to talk to more students so you can bounce ideas of each other, then at least you've got some ideas".

One striking thing that was mentioned in almost all of the interviews was a turning point, where the respondent was forced to interact with the rest of the 
cohort (in a field trip or assessed group work) and where preconceptions were challenged on both sides: "this year, the second year, suddenly you become accepted. I think once they realise that you are not an idiot, then from my perspective that opened up quite nicely" (Eric).

\section{Use of technology}

A final theme to emerge was about the use of technology to study, in particular how the older mature students felt that they struggled to adopt new practices. "When it comes to me on my own, sat at home trying to do it, I can't and I give up in the end and that is how I feel about technology, it's not second nature to me" (Brenda).

Having formed their initial study habits more than two decades ago, this group were most comfortable working in a non-digital environment, for example, handwriting their early essay drafts: "I've always worked like that. I find it easier to write it out, then it sticks in, and when I type it up it sticks in even more" (David), or how fears of earlier technologies affected current practice: "by Christmas time I knew I was a bit of a dinosaur with the technology, because I was using my typewriter, I was terrified of technology for a long time" (Frank).

We should avoid a simplistic narrative of older mature students not engaging with technology. One of the students (Annabel) regularly watched YouTube videos that had been recommended as part of the module and another student (Eric) used the digital reference management software tool, Mendeley, to manage their references via their smartphone.

\section{Discussion}

The results presented here paint a familiar snapshot of the unconfident, harried, isolated, mature student at an early stage of their undergraduate career. The earlier literature pointed to improved degree outcomes for this older mature group, and these stories suggest that the journey to these outcomes is a fraught and stressful one. 
These students have struggled to negotiate access to an undergraduate culture dominated by young undergraduates, who have far fewer distractions and can fully participate in the social activities and networks that are available to them (Christie et al., 2005, Tuckett, 1990).

Nonetheless, at the point of being interviewed, many of these students had reached significant turning points in their integration into the wider undergraduate culture and had made real progress in their studies. In fact by the time of writing this article, three of the sample had graduated with 1st class degrees, with one entering their final year. One had dropped out and one was retaking a year, both of which point to some of the problems with retention that (Hatt et al., 2002) identified.

Clearly, confidence was a significant issue for this group, and impacted on the other issues such as time management and social interaction. There are a number of good reasons to suppose that issues of confidence are particularly acute for older mature students.

Firstly they will be challenging long-held beliefs about themselves and their views about the world (Mezirow, 1978). This is arguably the point of education, but for the older learner the perspectives that are being challenged have held true for decades. Many of the respondents to this study acknowledged that going to university was itself a deliberate strategy to challenge previously held views about themselves and their academic ability.

Secondly, whilst mature students feel isolated from the younger student body and culture (Christie et al., 2005), these feelings will only be more acute for older mature students as the culture and generational distances increase. Being as old as some of the staff, and having children as old as classmates are quite clear markers of difference, which will present challenges to integration, alongside the increased likelihood of parental and employment responsibilities. 


\section{Conclusion}

This small study adds to a developing literature on older mature learners, and gives a voices to this often overlooked group. It suggests that confidence plays a crucial part in the experience of these students, and that as their confidence grows, their time management and engagement with the wider undergraduate culture improves.

There are some obvious limitations to this study, beyond the restricted sample size. These students were recruited into a foundation year, and therefore entered without any recent educational experience, they were returners to education, rather than mature students whose path into HE was temporarily interrupted (Baxter and Britton, 2001). Mature students starting university after an access course may well have a very different experience. Also the university that this study was based in was by no means typical of the sector. As an old, established university it had few mature students (let alone older mature) and almost all of the undergraduate body lived in halls, especially in their first year, in contrast to all of the students in this study, who lived out.

Nevertheless, this study raises important questions about lifelong learning and, to the extent that this group differ from the main student intake, widening participation. Strategies to enhance the confidence of this group, such as mixed group work and field trips and targeted IT support, will reduce the lack of confidence of these students and improve their time management issues and provide some level of integration into the wider student body. These strategies may also, by helping to reduce stress, positively impact upon the retention of these students. 


\section{Acknowledgments}

The author wishes to thank Jan Smith and Elaine Tan for helpful comments and suggestions on earlier drafts of this article.

\section{References}

Baxter, A. and Britton, C. (2001) 'Risk, identity and change: becoming a mature student', International Studies in Sociology of Education, vol. 11, no. 1, pp. 87-104.

Baxter, A. and Hatt, S. (1999) 'Old and young mature students: painting a fuller picture', Journal of Access and Credit Studies, pp. 137-48.

Bourner, T. and Hamed, M. (1987) Entry Qualifications and Degree Performance: Summary Findings Report, Council for National Academic Awards.

Brady, D. and Brady, M. (1998) 'Mature students and higher education: preparation, selection and experience', in Mitchell, P. (ed.) Beyond the Universities: the New Higher Education Monitoring Change in Education, Aldershot, Ashgate Arena, pp. 39-57.

Britton, C. and Baxter, A. (1999) 'Becoming a mature student: gendered narratives of the self', Gender and Education, vol. 11, no. 2, pp. 179-93.

Brooks, R. (2011) 'Student-parents and higher education: a cross-national comparison', Journal of Education Policy, vol. 27, no. 3, pp. 423-39.

Christie, H., Munro, M. and Wager, F. (2005) 'DDay students' in higher education: widening access students and successful transitions to university life', International Studies in Sociology of Education, vol. 15 , no. 1 , pp. 3-30.

Davies, P. and Parry, G. (1993) Recognising Access. The Formation and Implementation of the National Framework for the Recognition of 
Access Courses, Leicester, National Institute of Adult Continuing Education.

Hatt, S., Baxter, A. and Kimberlee, R. (2002) "'It's our last chance"-a study of completion rates by age at an English University', Journal of Adult and Continuing Education, vol. 8, no. 1, pp. 88-103.

HESA (2016) UKPIs Definitions. Available at https://www.hesa.ac.uk//data-and-analysis/performanceindicators/definitions (Accessed 30 May 2016).

Hoskins, S.L., Newstead, S.E. and Dennis, I. (1997) 'Degree performance as a function of age, gender, prior qualifications and discipline studied', Assessment \& Evaluation in Higher Education, vol. 22, no. 3, pp. 317-28.

Johnes, J. (2014) In the UK, Are Student Populations Growing Older? Social Science Space. Available at http://www.socialsciencespace.com/2014/09/in-the-uk-are-studentpopulations-growing-older/ (Accessed 26 July 2015).

Lewis, J., West, A., Roberts, J. and Noden, P. (2016) 'The experience of coresidence: young adults returning to the parental home after graduation in England', Families, Relationships and Societies.

Mallman, M. and Lee, H. (2014) 'Stigmatised learners: mature-age students negotiating university culture', British Journal of Sociology of Education, pp. 1-18.

Marshall, C. A. (2013) 'Good Foundations', Widening Participation and Lifelong Learning, vol. 15, no. 2, pp. 22-42.

Mercer, J. (2007) 'The challenges of insider research in educational institutions: wielding a double-edged sword and resolving delicate dilemmas', Oxford Review of Education, vol. 33, no. 1, pp. 1-17.

Mezirow, J. (1978) 'Perspective transformation', Adult Education Quarterly, vol. 28, no. 2, pp. 100-10. 
Nisbet, J. and Welsh, J. (1972) 'The Mature Student', Educational Research, vol. 14 , no. 3, pp. 204-207.

OFFA (2014) OFFA comment on increase in mature students securing places in higher education. Available at https://www.offa.org.uk/press-releases/offa-comment-on-increasein-mature-students-securing-places-in-higher-education/ (Accessed 26 July 2015).

Parry, G. and Wake, C. (eds.) (1990) Access and Alternative Futures. London: Hodder \& Stoughton.

Reay, D., Ball, S. and David, M. (2002) 'It's taking me a long time but I'll get there in the end': mature students on access courses and higher education choice', British Educational Research Journal, vol. 28, no. 1, pp. 5-19.

Richardson, J.E. (1994) 'Mature students in higher education: academic performance and intellectual ability', Higher Education, vol. 28, no. 3, pp. 373-86.

Scott, C., Burns, A. and Cooney, G. (1996) 'Reasons for discontinuing study: the case of mature age female students with children', Higher Education, vol. 31, no. 2, pp. 233-53.

Scott, P. (1998) 'Massification, internationalization and globalization', in Scott, P. (ed.) The Globalisation of Higher Education, Buckingham, Open University Press.

Smith, J. (2008) Mature learners: a synthesis of research, HEA. Available at https://www.heacademy.ac.uk/system/files/wp_mature_learners_syn thesis_on_template_updated_090310.pdf .

Tuckett, A. (1990) 'A higher education system fit for adult learners', in Parry, G. and Wake. C. (eds.) Access and Alternative Futures for Higher Education, London,Hodder \& Stoughton, pp. 113-33. 
Tunstall, J. (1974) The Open University Opens, Amherst, Massachusetts, University of Massachusetts Press.

Wakeford, N. (2006) 'Beyond Educating Rita: mature students and access courses', Oxford Review of Education, vol. 19, no. 2, pp. 217-30. 